\title{
Applicability of Multi-modal Public Transport System Based on Accessibility Analysis
}

\author{
Yi Zhao', Jian $\mathrm{Lu}^{1}{ }^{*}$, Hongtong Qiu ${ }^{2}$ \\ ${ }^{1}$ Jiangsu Key Laboratory of Urban ITS and Jiangsu Province Collaborative Innovation Center of Modern \\ Urban Traffic Technologies, Nanjing, China. \\ 2 National Road Traffic Management Engineering Technology Research Center, China. \\ * Corresponding author. Tel: 18061472553; email: lujian_1972@seu.edu.cn \\ Manuscript submitted July 10, 2014; accepted January 8, 2015.
}

doi: 10.17706/ijcce.2015.4.3.211-218

\begin{abstract}
Public transport has a natural disadvantage in terms of speed, comfort and flexibility with respect to individual traffic. While the synergy of various public transport modes can be set to produce the best possible results of public transport system, which may bring superiority relate to individual traffic. Considering the characteristics of the bus speed, the transfer characteristics, this study explored the possibility of multi-modal public transport system to replace individual traffic and the differential application scopes of them from the stands of space accessibility and time accessibility. According to the conclusion, recommendations on public transport modes selection, layout and others are given to improve the effect of multi-modal public transport system.
\end{abstract}

Key words: Multi-modal public transport, accessibility, applicability.

\section{Introduction}

The urban public transport system includes a variety of patterns such as normal buses, rail transit, the BRT, trams, taxi and so on. Each kind of traffic tools provides different services to passengers with different speeds, carrying capacity, prices and comfort levels. However, the single index service quality of each trip mode is not completely good [1], the single public transport mode is difficult to meet the residents' pursuit of travelling quality in future, and we must develop multi-model public transport system, give full play to the advantages of different public transport modes, making them supplement to each other. Only reasonable organized city public transport system can offer safe, quick, convenient, on-time, comfortable and economic transportation services to passengers, saving time as much as possible in social activities, meeting the needs of city production, social development and citizens' work and life.

\section{Multi-modal Public Transport System}

With the development of urban economy and technology, various modes of urban public transport have become available apart from the traditional ground public transport system, such as BRT and rail transit, both with large volume, forming the urban public transport network in which multiple public transport ways coexist [2]. Multi-model public transport is a comprehensive system which covers various modes of public transport and it's the inevitable choice in order to adapt to urban development, and to meet the travel demand of citizens.

Preliminary public transport systems in domestic metropolises have been built. Traffic is divided and 
reduced by all kinds of public transport means, such as rail transit, bus, taxi, etc. Therefore it's not only an inevitable trend to provide diversified means of public transport networks, but also the only way out for big cities to further develop their public transport systems [3]. Development of multi-model public transport has following advantages: 1) can meet the demands of passenger flows of different levels; 2) forms transit oriented (TOD) development; 3) further improves urban competitiveness.

Based on the actual condition of traffic in big cities, it is difficult to limit development of individual traffic completely or substantially under current condition of resources and transportation [4]. Therefore the premise of transforming transport mode in big cities remains proper level of individual motorized travel modes. Meanwhile, multi-modal transport systems shall be enhanced to form a city transport mode led by multi-modal public transport connected excellently with slow-moving mode.

\section{The Basic Theories of Accessibility}

The passengers' essential demand for the bus service level is hoping to get the accessibility of time and space at the same time, which is called the bus accessibility. Time accessibility is to ask for improving the running speed of public transport from the efficiency of service and shortening the time of bus trip, while space accessibility asks for increasing the coverage of bus routes and bus stations to conveniently obtain bus services.

\subsection{Space Accessibility}

The multi-model public transport network system aims to replace cars as the dominant means of transportation by improving its flexibility and accessibility so that easy connection between different modes of transportation is possible.

For a short-distance trip, one can travel by means of regular ground transportation, and for the distance between the starting place and bus stop, one can walk (within 500 meters )or ride a public bike(within 1 kilometer ) to get to the bus stop; the long-distance trip can be turned into the trip combination of various public transport modes [5]. As shown in 0 below, a complete complicated trip can involve a variety of modes such as the public bike (twice), ground public transport (twice) and rail transit (once). When the coverage of rail transit stations is high enough, public transport trip can be simplified as "walking"-"rail transit"-"walking". Therefore, it can be seen that, through construction of high-density public transport facilities, space accessibility of public transport can absolutely be improved.

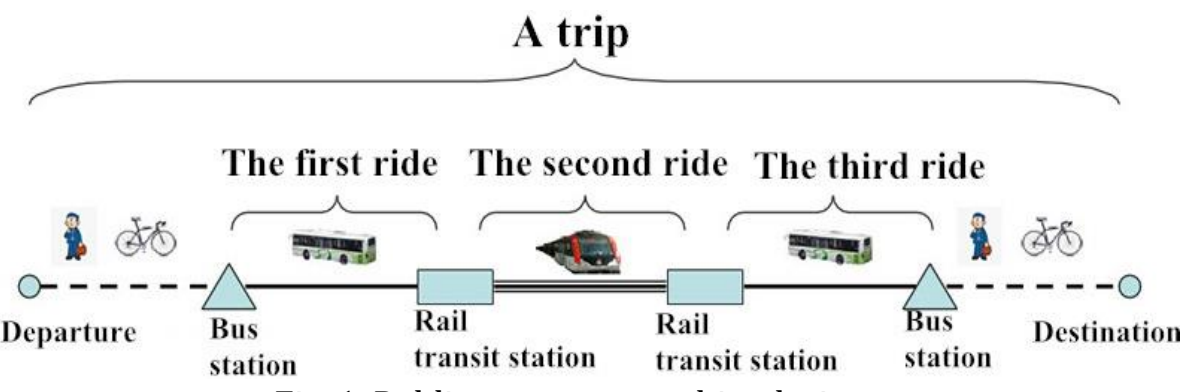

Fig. 1. Public transport combined trip.

\subsection{Time Accessibility}

For the same trip, when the time taken to fulfill the purpose of the trip through the combined modes of public transport is not more than the time taken through sedan cars, it is deemed that the time accessibility of public transport is better than that of sedan cars.

Assuming that the total distance of a trip is $L$, if we take the trip by the way of sedan car, the time of the trip 
can be expressed as:

$$
\begin{aligned}
& T_{1}=T_{\text {in city }}+T_{\text {suburb }}+T_{\text {speedway }}+T_{0} \\
& =\frac{L_{\text {in city }}}{V_{\text {in city }}}+\frac{L_{\text {suburb }}}{V_{\text {suburb }}}+\frac{L_{\text {speedway }}}{V_{\text {speedway }}}
\end{aligned}
$$

Notes: $T_{1}$ - the total time consumed by travelling by sedan; $T_{\text {In City, }} L_{\text {In City }}, V_{\text {In City }}$ - the trip time, trip distance and travel speed of the sedan car inside the city; $T_{\text {suburb }}, L$ suburb,$V_{\text {suburb }}$-the trip time, trip distance and travel speed of the sedan car in the suburbs; $T$ Speedway, $L$ Speedway,$V$ Speedway -the trip time, trip distance and travel speed of the sedan car in the suburbs.

Considering the sedan car trip will be influenced by the extent of the road conditions and traffic congestions, it is significantly different in speed of sedan car travelling, depends on different road conditions [6]. So, in the formula (1), trip time of small cars can be divide into three parts combination, that is intra-city trip time $T_{\text {in-city, }}$ suburban trip time $T_{\text {the suburb }}$, the speedway trip time $T_{\text {speedway. }}$ In-city, suburb and speedway represent the differences of these three road situations.

If take the multi-model public transport to replace the sedan car, on the basis of perfect multi-model urban public transport system, the single trip time of public transport can be expressed as follows:

$$
T_{2}=\sum_{N_{1}} T_{\text {Slow Tra }}+\sum_{N_{2}} T_{\text {Nor Bus }}+\sum_{N_{3}} T_{\text {BRT }}+\sum_{N_{4}} T_{\text {Urban Track }}+\sum_{N_{5}} T_{\text {Intercity Rail }}
$$

Note: $T_{2}$ - The total time consumed by multi-model bus trip; $T$ slow Tra - Time consumed by slow traffic; $T$ Nor bus - Time consumed by normal bus trip; $T_{\text {BRT }}$ - the time of bus rapid transit; $T_{\text {Urban Track }}$ - spending time of the urban track; $T$ Intercity Rail - the time of the intercity rails; $N_{1}, N_{2}, N_{3}, N_{4}, N_{5}$, respectively, represent the times of being used in a multi-model bus trip by slow-speed buses, normal buses, rapid buses, the urban track and intercity rail transit.

In formula (2), it considers the most common trip modes such as slow transports (walk, non-motorized vehicle, etc.), regular public transport, rapid public transport and rail transport (urban rail and inter-city rail) in urban public transport travelling, $N_{1}, N_{2}, N_{3}, N_{4}, N_{5}$ represent the use times of some public transport travelling tools during a single travelling. Under the condition of the mature development of multi-model public transport system, it can be assumed as following: $N_{1}=0,1,2$, which means 2 times slow moving parts exist mostly, and they exist in the starting and end point of the trip respectively. The value range of $N_{2}, N_{3}, N_{4}$, $N_{5}$ is $0,1,2$, which indicates a public transport mode cannot be used for more than two times during a single trip; meanwhile, $N_{2}+N_{3}+N_{4} \leqq 4$ indicates that in one single trip, besides slow moving and intercity rail transit section, there are 4 times transformation. And if it transfers 4 times, it must be 1 time trans-line of transfer in the intercity rail transit; when $N_{5}=0$ or 1 , it indicates that under the multi-model public transport, one trip uses the intercity rail once at most.

Meantime, the time spent $T$ for each transport mode in formula (2) is composed of two parts: trip time in the sedan car $t$ trip and the waiting time $t$ wait.

$$
T=t_{\text {Driving }}+t_{\text {Waiting }}=\frac{L_{\text {Trip }}}{V_{\text {Trip }}}+t_{\text {Waiting }}
$$


Note: $T$ - trip time of one kind of public transport mode; $t_{\text {Driving }}$ - time consumption in the process of driving; $t$ Waiting - time consumption in waiting for a bus or train; $L$ Trip - mileage of travelling; $V$ Trip public transport travel speed.

\section{Accessibility Advantage Analysis}

Analysis of the above trip time based on the background of rush hours in the morning and evenings is as following. Among which, the waiting time of slow traffic is 0 ; The average waiting time of regular public transport and that of rapid public transport are impacted by the vehicle departure frequency, supposing the departure frequency of regular public transport and that of rapid public transport are respectively 4 min and $5 \mathrm{~min}$, then the average waiting time of regular public transport and that of rapid public transport will be respectively $2 \mathrm{~min}$ and $2.5 \mathrm{~min}$; The waiting time of urban rail transport includes the walking time after transfer and vehicle waiting time. Supposing the transfer walking time is $5 \mathrm{~min}$, and the average vehicle waiting time is $1.5 \mathrm{~min}$ (the subway frequency is $3 \mathrm{~min}$ ); Assuming the average waiting time of intercity rail transit (including rail motor coach) is 15 minutes.

The trip time depends on the travelling speed of different trip modes; currently our country's high speed rail has a maximum speed of $300 \mathrm{~km} / \mathrm{h}$, and bullet train has a maximum speed of $250 \mathrm{~km} / \mathrm{h}$, so it can be assumed that the average travelling speed of intercity rails is $180 \mathrm{~km} / \mathrm{h}$; the average speed of the urban subway is over $40 \mathrm{~km}$ per hour, and the max speed will reach to $80 \mathrm{~km}$ per hour, so the average speed in the city rail can be assumed as $35 \mathrm{~km} / \mathrm{h}$; the speed of bus rapid transit is $15 \sim 25 \mathrm{~km}$ per hour, and if it is designed reasonably and controlled effectively, the general speed can reach over $25 \mathrm{~km}$ per hour, so we can assume the average speed of bus rapid transit is $25 \mathrm{~km} / \mathrm{h}$; normal bus runs $10 \sim 18 \mathrm{~km}$ per hour, so the hypothesis of the average speed is $15 \mathrm{~km} / \mathrm{h}[7]$.

The purpose of slow-moving traffic is to access other public transport means, assuming to access the public transport facilities within 5 min maximum $(500 \mathrm{~m})$ under mature environment of multi-modal public transport, which is of average slow-moving speed $2.5 \mathrm{~min}$. The actual velocity of sedan cars in cities is about 18 30 km per hour, assume the average velocity of which in peak-hour as $20 \mathrm{~km} / \mathrm{h}$. The average velocity in suburb or elevated roads is $40 \sim 50 \mathrm{~km}$ per hour, assume the value as $40 \mathrm{~km} / \mathrm{h}$. The velocity in highways is no more than $120 \mathrm{~km} / \mathrm{h}$; assume the actual velocity as $100 \mathrm{~km} / \mathrm{h}$.

This paper makes detailed comparative analysis from two aspects about the accessibility of trip modes. One is the time accessibility of single public transport trip and sedan car, and the other aspect is the time accessibility of multi-modal public transport trip and sedan car.

\subsection{The Time Accessibility of Single Bus Trip and Sedan Car Trip}

As shown in Table 1, when sedan car trip can be achieved by the way of single public transport and the average speed of the sedan car is $20 \mathrm{~km} / \mathrm{h}$ due to the influence of signal control and traffic jam in the city, and the distance of single trip is over $4.17 \mathrm{~km}$, the time accessibility of bus rapid transit is better than sedan car trip. When trip distance is over $5.04 \mathrm{~km}$, urban rail transit will be better than sedan car trip [8]. However, when the road condition is good and the average speed of the sedan car is high, even urban rail transit and bus rapid transit struggle to compete with sedan car.

\subsection{Time Accessibility of Multi-model Public Transport and Car Transportation}

Because single public transport has limited space accessibility, which means for long distance travelling, it is difficult to achieve the travelling purpose by using public transport only for once, therefore, it is necessary to make a time-accessibility comparison between the travelling by using public transport (multi-model public transport mode) for more than once and the travelling by only using a car, and the comparison results are as shown in Table 2. 
Table 1. Single Public Transport Mode Compared with the Time Accessibility of Sedan Cars

\begin{tabular}{|c|c|c|c|c|c|}
\hline Trip mode & Slow-moving traffic & Normal bus & Bus Rapid Transit & Urban rail transit & Intercity rail transit \\
\hline \multirow[t]{2}{*}{ Trip distance (km) } & \multicolumn{5}{|c|}{$L=L_{\text {Slow }}+L_{\text {Normal }}+L_{\mathrm{BRT}}+L_{\text {Urban rail }}+L_{\text {Intercity }}\left(\right.$ Note: $\left.L_{\text {Slow }}<500 \mathrm{~m}\right)$} \\
\hline & $L_{\text {Slow }}$ & $L_{\text {Normal }}$ & $L_{\mathrm{BRT}}$ & $L_{\text {Urban rail transit }}$ & $L_{\text {Intercity }}$ \\
\hline $\begin{array}{c}\text { Travel } \\
\text { Speed }(\mathrm{km} / \mathrm{h})\end{array}$ & - & 15 & 25 & 35 & 180 \\
\hline $\begin{array}{l}\text { Waiting } \\
\text { Time(min) }\end{array}$ & 0 & 2 & 2.5 & 6.5 & 15 \\
\hline $\begin{array}{l}\text { Trip time by bus } \\
t_{2}(\min )\end{array}$ & 5 & $2+L_{\text {normal }} \times 60 / 15$ & $2.5+L_{\mathrm{BRT}} \times 60 / 25$ & $\begin{array}{c}6.5+L_{\text {Urban rail transit }} \\
\times 60 / 35\end{array}$ & $15+L_{\text {intercity }} \times 60 / 180$ \\
\hline $\begin{array}{l}\text { The sedan car's } \\
\text { travel time } t_{1}(\mathrm{~min})\end{array}$ & $L_{\text {Slow }} \times 60 / V_{\mathrm{C} 1}$ & $L_{\text {normal }} \times 60 / \mathrm{V}_{C 1}$ & $L_{\mathrm{BRT}} \times 60 / V_{\mathrm{C} 1}$ & $\begin{array}{l}L_{\text {Urban rail transit }} \\
\quad \times 60 / V_{\mathrm{Cl}}\end{array}$ & $L_{\text {Intercity }} \times 60 / V_{\mathrm{C} 2}$ \\
\hline $\begin{array}{l}\text { Condition of } t_{2}<t_{1} \\
\text { when } V_{C 1}=20 \mathrm{~km} / \mathrm{h}\end{array}$ & $\begin{array}{l}t_{2} \text { is always greater } \\
\text { than } t_{1}\end{array}$ & $\begin{array}{l}t_{2} \text { is always } \\
\text { greater than } t_{1}\end{array}$ & $L_{\mathrm{BRT}}>4.17$ & 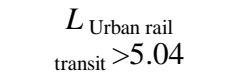 & $L_{\text {Intercity }}>55.56$ \\
\hline Remarks & \multicolumn{5}{|c|}{$\begin{array}{l}V_{C 1} \text { shows the travel speed of cars in the city, } 20 \mathrm{~km} / \mathrm{h}=V_{\text {urban }}<V_{\mathrm{Cl}}<V_{\text {suburban }}=40 \mathrm{~km} / \mathrm{h} \text {; } \\
V_{C 2} \text { indicates the velocity of car in intercity traffic, and } V_{C 2}=V_{\text {BRT d }}=100 \mathrm{~km} / \mathrm{h} \text {. }\end{array}$} \\
\hline
\end{tabular}

Table 2. Comparison between the Time Accessibility of Multi-model Public Transport and Sedan Cars

\begin{tabular}{|c|c|c|c|c|c|c|c|c|}
\hline \multirow{2}{*}{$\vec{\Xi} \cdot \overrightarrow{D^{\prime}}$} & \multirow{2}{*}{\multicolumn{2}{|c|}{$\begin{array}{c}\text { Multi-model Trip vs. Car } \\
\text { Trip }\end{array}$}} & $\begin{array}{l}\text { Non-motorized } \\
\text { Traffic }\end{array}$ & $\begin{array}{l}\text { Normal } \\
\text { Bus }\end{array}$ & $\begin{array}{l}\text { Bus Rapid } \\
\text { Transit }\end{array}$ & $\begin{array}{l}\text { Urban } \\
\text { track }\end{array}$ & Intercity Rail & \multirow{2}{*}{$\begin{array}{l}\text { The condition of } t_{2}<t_{1} \\
\qquad\left(V_{\mathrm{C} 1}=20 \mathrm{~km} / \mathrm{h}\right)\end{array}$} \\
\hline & & & $L_{\text {slow }}$ & $L_{\text {normal }}$ & $L_{\mathrm{BRT}}$ & $L_{\text {Urban track }}$ & $L_{\text {Intercity }}$ & \\
\hline \multirow{15}{*}{1} & \multirow{3}{*}{ 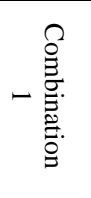 } & Selection of modes & 2 & 1 & 1 & & & \multirow{3}{*}{$\begin{array}{c}L_{\text {normal }}<0.6 \times L_{\mathrm{BRT}}-6.5 ; \\
L_{\mathrm{BRT}}>10.8\end{array}$} \\
\hline & & $\begin{array}{l}\text { Trip time of bus } t_{2} \\
\text { (min) }\end{array}$ & \multicolumn{5}{|c|}{$5+\left(2+L_{\text {normal }} \times 60 / 15\right)+\left(2.5+L_{\mathrm{BRT}} \times 60 / 25\right)=9.5+4 \times L_{\text {normal }}+12 / 5 \times \mathrm{L}_{\mathrm{BRT}}$} & \\
\hline & & $\begin{array}{c}\text { The car's travel time } \\
t_{1}(\mathrm{~min})\end{array}$ & \multicolumn{5}{|c|}{$\left(1+L_{\text {normal }}+L_{\mathrm{BRT}}\right) \times 60 / \mathrm{V}_{\mathrm{C} 1}$} & \\
\hline & \multirow{3}{*}{ 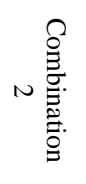 } & Selection of modes & 2 & 1 & & 1 & & \multirow{3}{*}{$\begin{array}{c}L_{\text {Normal }}<1.29 \times L_{\text {Urban track }} \\
-10.5 \\
L_{\text {Urban track }}>8.14\end{array}$} \\
\hline & & $\begin{array}{l}\text { Trip time of bus } t_{2} \\
\text { (min) }\end{array}$ & $5+\left(2+L_{\text {normal }} \times 6\right.$ & )$+\left(6.5+L_{L}\right.$ & $\mathrm{ck} \times 60 / 35)=1$ & $-4 \times L_{\text {normal }}+1$ & $/ 7 \times L_{\text {Urban track }}$ & \\
\hline & & $\begin{array}{l}\text { The car's trip time } \\
t_{1}(\mathrm{~min})\end{array}$ & \multicolumn{5}{|c|}{$\left(1+\mathrm{L}_{\text {normal }}+\mathrm{L}_{\text {Urban track }}\right) \times 60 / \mathrm{V}_{\mathrm{C} 1}$} & \\
\hline & \multirow{3}{*}{ 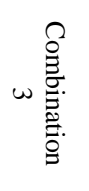 } & Selection of modes & 2 & & 1 & 1 & & \multirow{3}{*}{$\begin{array}{c}11<0.6 L_{\mathrm{BRT}}+1.29 L_{\text {Urban }} \\
\text { track }\end{array}$} \\
\hline & & $\begin{array}{l}\text { Trip time of bus } t_{2} \\
\text { (min) }\end{array}$ & $5+\left(2.5+L_{\mathrm{BRT}} \times 6\right.$ & )$+\left(6.5+L_{\mathrm{U}}\right.$ & $\mathrm{ck} \times 60 / 35)=1$ & $2 / 5 \times L_{\mathrm{BRT}}+1$ & $/ 7 \times L_{\text {Urban track }}$ & \\
\hline & & $\begin{array}{l}\text { The car's trip time } \\
\qquad t_{1}(\mathrm{~min})\end{array}$ & & $\left(1+L_{\mathrm{B}}\right.$ & Urban track $) \times($ & & & \\
\hline & \multirow{3}{*}{ 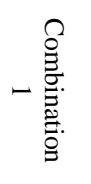 } & Selection of modes & 2 & 2 & 1 & & & \multirow{3}{*}{$\begin{array}{c}L_{\mathrm{Normal}}<0.6 \times L_{\mathrm{BRT}^{-}}-8.5 \\
L_{\mathrm{BRT}}>14.17\end{array}$} \\
\hline & & $\begin{array}{l}\text { Trip time of bus } t_{2} \\
\text { (min) }\end{array}$ & $5+\left(2 \times 2+L_{\mathrm{no}}\right.$ & $60 / 15)+($ & $\left.\mathrm{BRT}_{\mathrm{BR}} \times 60 / 25\right)$ & $5+4 \times L_{\text {norma }}$ & $12 / 5 \times L_{\mathrm{BRT}}$ & \\
\hline & & $\begin{array}{l}\text { The car's trip time } \\
t_{1}(\mathrm{~min})\end{array}$ & & $(1+L$ & $\left.1+L_{\mathrm{BRT}}\right) \times 6$ & & & \\
\hline & \multirow{3}{*}{ 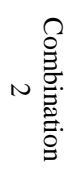 } & Selection of modes & 2 & 2 & & 1 & & \multirow{3}{*}{$\begin{array}{c}L_{\text {Normal }}<1.29 \times L_{\text {Urban track }} \\
-12.5 \\
L_{\text {city rail }}>9.69\end{array}$} \\
\hline & & $\begin{array}{l}\text { Trip time of bus } t_{2} \\
\text { (min) }\end{array}$ & $5+\left(2 \times 2+L_{\text {normal }} \times 6\right.$ & )$+(6.5+L$ & ack $\times 60 / 35)=$ & $+4 \times L_{\text {normal }}$ & $2 / 7 \times L_{\text {Urban track }}$ & \\
\hline & & $\begin{array}{l}\text { The car's trip time } \\
t_{1}(\mathrm{~min})\end{array}$ & & $\left(1+L_{\mathrm{n}}\right.$ & $\left.L_{\text {Urban track }}\right)>$ & $V_{\mathrm{C} 1}$ & & \\
\hline \multirow{5}{*}{2} & \multirow{3}{*}{ 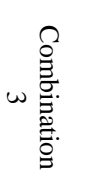 } & Selection of modes & 2 & 1 & 2 & & & \multirow{3}{*}{$\begin{array}{c}L_{\text {normal }}<0.6 \times L_{\mathrm{BRT}-9} \\
L_{\mathrm{BRT}}>15\end{array}$} \\
\hline & & $\begin{array}{l}\text { Trip time of bus } t_{2} \\
\text { (min) }\end{array}$ & $5+\left(2+L_{\text {Norm }}\right.$ & $0 / 15)+(2 \times$ & $\left.\mathrm{BRT}_{\mathrm{BR}} \times 60 / 25\right)$ & $+4 \times L_{\mathrm{Normal}}+$ & $2 / 5 \times L_{\mathrm{BRT}}$ & \\
\hline & & $\begin{array}{l}\text { The car's trip time } \\
t_{1}(\mathrm{~min})\end{array}$ & & $(1+1$ & $\left.{ }_{1}+L_{\mathrm{BRT}}\right) \times 6$ & & & \\
\hline & \multirow{2}{*}{ 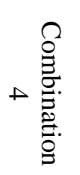 } & Selection of modes & 2 & 1 & & 2 & & \multirow[b]{2}{*}{$\begin{array}{c}L_{\text {Normal }}<1.29 \times L_{\text {Urban track }} \\
-17 \\
L_{\text {Urban track }}>13.18\end{array}$} \\
\hline & & $\begin{array}{l}\text { Trip time of bus } t_{2} \\
\text { (min) }\end{array}$ & $5+\left(2+L_{\text {normal }} \times 60\right.$ & $+(2 \times 6.5+1$ & track $\times 60 / 35)$ & $+4 \times L_{\text {normal }}+$ & $2 / 7 \times L_{\text {Urban track }}$ & \\
\hline
\end{tabular}




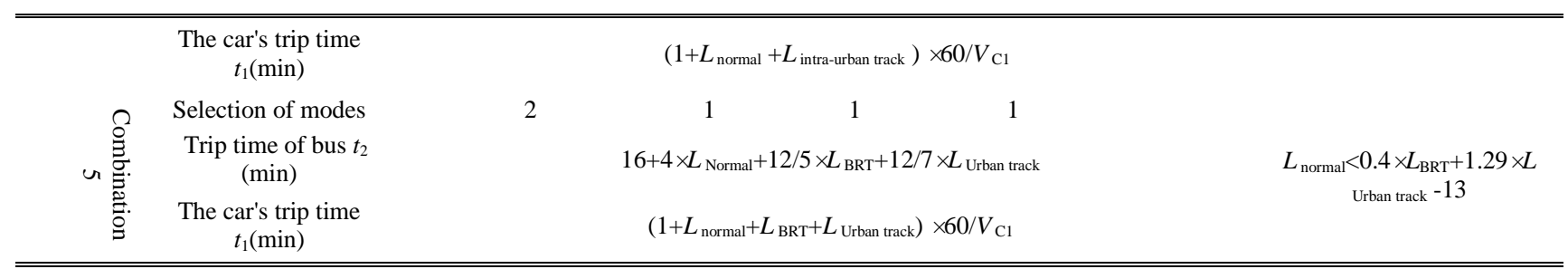

In Table 2, the multi-model bus trip which needs only one-time transfer (using 2 types of public transport modes, non-motorized traffic mode not include) and the multi-model bus trip which needs two-time transfer were compared with the trip behavior of the sedan car, the result is as follows:

Under multi-model public transport system, the regulation of frequency of single travel transference can be realized by the appropriate distribution of rail transit, bus rapid transit, normal bus transit and so on. It can be regarded that 2 times of transfer can meet the needs of one trip, while transference over 2 times is not considered in discussion scope.

The multi-model public transport travelling of 1 time transfer analyzes such three different modes of combined activities as normal public transport combined with bus rapid transit, normal public transport combined with urban track, and bus rapid transit combined with urban track. In the case of the sedan car's speed staying at $20 \mathrm{~km} / \mathrm{h}$, if a certain condition of the multi-model public transport is met, the time accessibility of it will be better than the sedan car. In the case of normal public transport and urban track transport are adopted for travelling, as shown in Table 2, when the normal public transport distance $L$-normal and the urban track distance L-urban are locating at the right side of the straight line $(y=1.29 x-10.5)$, the trip time of multi-model public transport $t_{2}$ will be less than the car $t_{1}$, as seen in Fig. 2 .

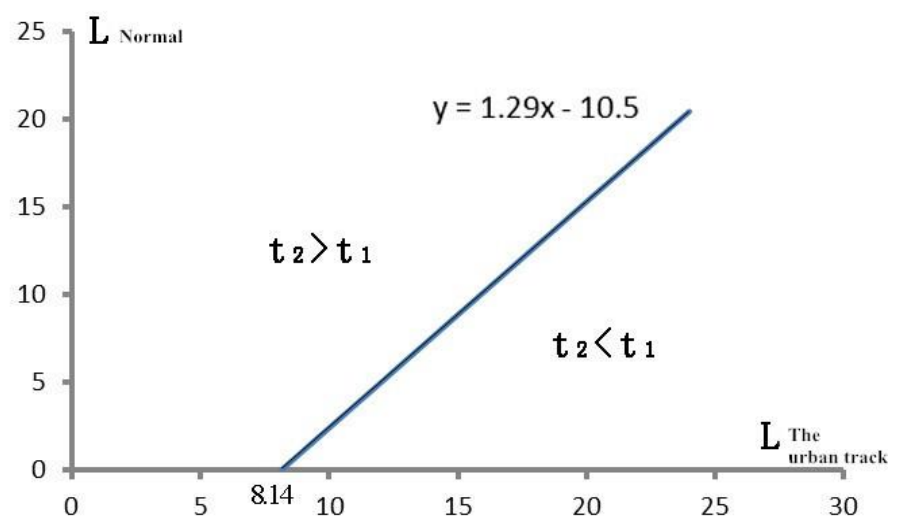

Fig. 2. Comparison between the time accessibility of the multi-model public transport trip (by normal bus and urban track) and the sedan car trip.

The multi-model public transport travelling of 2-time transfer analyzes such five different modes of combined activities as 2 times of normal public transport combined with 1 time of bus rapid transit, 2 times of normal public transport combined with 1 time of urban track, 1 time of normal public transport combined with 2 times of bus rapid transit, 1 time of normal public transport combined with 2 times of urban track, and 1 time of normal public transport combined with 1 time of bus rapid transit and 1 time urban track. Likewise, when the trip distance in different trip modes meets certain condition, the time accessibility of the multi-model bus trip will be better than car trip. Taking the one-time normal bus combined with two-time intra-urban track as an example, it is showed in Table 2. When $L$ normal and $L$ urban track are at the right side of line $(y=1.29 x-17), t_{2}$ of the trip time of multi-model bus will be less than the $t_{1}$ of the trip time of cars. See Fig. 3. 


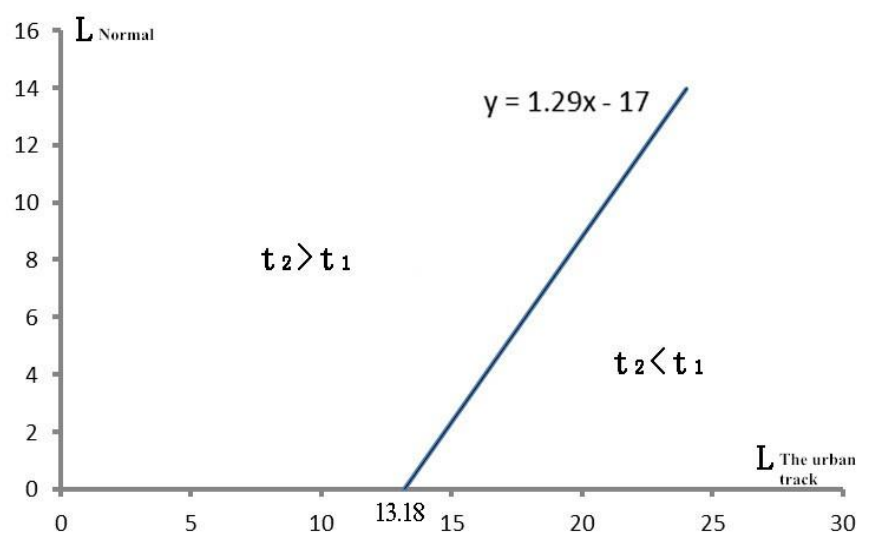

Fig. 3. Multi-model bus trip (1 time normal bus and 2 times intra-urban track) compares with the time accessibility of the car.

For the above-mentioned transfer behavior, the intercity rail transit is not considered altogether, as it is known from Table 1, when the intercity distance is more than $55.56 \mathrm{~km}$, for the trip of the same distance, the time taken by means of the intercity rail transit will be far less than the car mode. The time saved by the intercity rail transit can make up the partial delay by the multi-model public transport trip within the city, which further improves the competitiveness of the multi-model public transport in intercity trips compared with the car trip.

\section{Conclusion and Suggestion}

\subsection{Conclusion}

It is known from the above result of comparing the sedan car trip and public transport trip that the time accessibility of public transport is not completely inferior to that of sedan cars when taking proper public transport means or reasonable combination of multiple public transport means, and even it is likely to take less time than sedan cars, no matter taking the short-distance trip (being accomplished by a single public transport means) or the long-distance trip (being accomplished by the multi-model public transport means).

And the sedan car trip is easily influenced by the surrounding environment, for example, when traffic jams happen on the city roads, the sedan car trip can cause quite a long delay which is hard to estimate. In terms of the stability of the time accessibility, public transport is much better than that of the sedan car trip.

\subsection{Suggestion}

Construction of the multi-model public transport involves a variety of public transport means such as track transit, bus rapid transit, and normal road transit. Only through the coordination of different transportation means, the advantage of the multi-model public transport can be fully displayed. For effectively optimize the connection between different modes, guarantee the development of the multi-model public transport can be provided from the following aspects: 1) forecast planning; 2) effective institutions and management; 3) policy, fund and land guarantee; 4) Public transport information construction, public transport priority and public transfer guarantee.

\section{References}

[1] Borne, P., Fayech, B., Hammadi, S., \& Maouche, S. (1993). Decision support system for urban transportation network. IEEE TSMC, Part C, 1, 67-77.

[2] Illsley, N., Holmes, K., Gibbard, C., \& Drummond, P. (2007). Transport Direct Electronic Transfer of Bus Service Data Briefing Note (pp. 58-79). Version 1.0. 
[3] Geurs, K. T., \& Ritsema van Eck, J. R. (2008). Accessibility Measures: Review and Applications. RIVM Report 408505 006, National Institute of Public Health and the Environment.

[4] Cebollada, A. (2009). Mobility and labour market exclusion in the arcelona metropolitan region. J. of Transport Geogr., 17(3), 226-233.

[5] Steinfeld, A., et al (2010). The value and acceptance of citizen science to promote transit accessibility. J. Technology and Disability, 22, 73-81.

[6] Latora, V., \& Marchiori, M. (2011, Feb.). Efficient behavior of small-world networks. Physical Review letters, 19, 1-4.

[7] Vanderbulcke, G., Steenberghen, T., \& Thomas, I. (2009). Mapping accessibility in Belgium: A tool for land-use and transport planning? J. of Transport Geogr., 17(1), 39-53.

[8] Fojtík, D., Ivan, I., \& Horák, J. (2011). Database of public transport connections - Its creation and use. Proceedings of the 12th International Carpathian Control Conference (pp. 115-119).

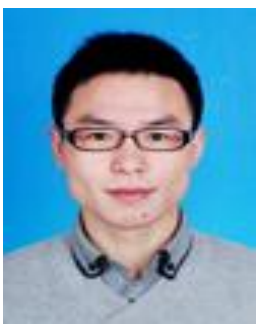

Yi Zhao was born in Anhui Province, China, in 1989. He received the B.S. degree from Hefei University of Technology, Hefei, in 2010, and received the M.S. degree from Southeast University, Nanjing, in 2013, both majoring in transportation engineering. He is currently pursuing the Ph.D. degree with the School of Transportation, Southeast University. His research interests include transportation management demand, traffic flow theory, traffic safety and ITS.

Jian Lu was born in 1972, China. He received his B.S. degree, M.S. degree and Ph.D. degree from Southeast University, Nanjing, in 1995, 1998 and 2003, respectively. He is the associate dean, professor and doctoral tutor of the School of Transportation in Southeast University. He is the young academic leader of Jiangsu Province. He has elected to join the "New Century Excellent Talents" Support Plan of Ministry of Education, and "333 high-level talent project" of Jiangsu Province. His research interests include traffic management, transport planning, traffic safety and intelligent transportation systems and so on.

Hongtong Qiu is the director and researcher of the Ministry of Public Security Traffic Management Research Institute. He has long been engaged in research about urban traffic management and intelligent transportation systems. The number of national or industry standards he presided over the preparation or revision reaches more than 20, and now many researches in the Ministry of Public Security are under his guidance. 